\title{
CYTOLOGIC DIFFERENTIAL DIAGNOSTIC PROBLEMS IN ULCERATIVE CERVICITIS
}

\begin{abstract}
Demetrio Tamiolakis ${ }^{1}$, Athanasia Kotini ${ }^{2}$, Nikoleta Koutlaki ${ }^{3}$, Georgios Galazios ${ }^{3}$, Vasilios Liberis $^{3}$, Panagiotis Anastasiadis $^{3}$
Chania Hospital, Chania, Greece: Depatment of Cytology ${ }^{1}$; Democritus University of Thrace, Medical School, Alexandroupolis, Greece: Laboratory of Medical Physics ${ }^{2}$, Department of Obstetrics \& Gynaecology ${ }^{3}$

Summary: Objective: To improve the detection rates in the determination of signs consistent with ulcerative cervicitis against signs of intraepithelial neoplasia, in PAP smears. Study design: We investigated the frequency of establishing a diagnosis of a simple ulcerative cervicitis by histology in a cohort of 58 females with cervical cytology suggestive of intraepithelial neoplasia. Results: There was found a detection rate of $81.58 \%$ in the determination of ulcerative cervicitis by cytology and a rate of $100 \%$ in the determination of HPV-infection, CIN1, CIN2 and CIN3 respectively. There was no statistically significant difference between cytology and histology in the diagnosis of ultracerative cervicitis ( $p>0.5$, chi-square). Conclusions: There is an overestimation of the cytological signs in the diagnosis of ulcerative cervicitis $18.42 \%$ ). There is also an excellent agreement in the diagnosis of HPV-infection and CIN grades (100 \%) between cytology and histology, discordant with the literature ( $2.4 \%-71 \%)$.
\end{abstract}

Key words: Ulcerative cervicitis; Cervical intraepithelial neoplacia (CIN); HPV-infection; Cytology; Histology

\section{Introduction}

Ulcerative cervicitis is, like all inflammatory processes, a reaction of the cervical epithelium against damaging factors (with the formation of an exudate, protein -, WBC-, and fibrin-rich), which is accompanied by ulceration.

Damaging factors can be micro-organisms (trichomonas vaginalis, herpes simplex, candida species, neisseria), iatrogenic or anatomic (biopsy, intrauterine contraceptive device-IUD-, prolapse of the uterus, cysteorthocele) and chemical (chemotherapy). Additional causative factors are estrogen depletion (hypoestrogenism), increased flow and alkalinity of cervical mucus, cervical ectopy and obstruction from pessaries or tampons.

It may be either acute or chronic. Chronic cervicitis is of more clinicopathologic interest because it causes sterility due to abnormalities of the os, involvement of the endometrium or tubes by inflammation conveyed up from the cervix, and it is partly a risk factor for cervical intraepithelial neoplasia.

The aim of our study is to increase the detection rate in the determination of features consistent with ulcerative cervicitis against features of CIN in cervicovaginal smears, considering that scarce related articles are found in the literature and cytologic interpretation of the entity is poorly qualified.

\section{Materials and Methods}

Out of 19375 women (38750 smears) examined in a 6 year period (1995-2001), 31 cases (0.16\%) were retrieved from the files of the department of Obstetrics and Gynecology initially diagnosed by cytology as cases of ulcerative cervicitis in a cohort of 58 ones aged from 18 to 39 years (average $=32.98, \mathrm{SD}=6.94$ ) with cytological hallmarks indicative of cervical intraepithelial neoplasia, in which a histological report was available.

Cytologic evaluation of ulcerative cervicitis was based upon inflammatory changes seen in epithelial cells and non-epithelial elements of the smears (WBC, RBC, fibrin, histiocytes). Inflammatory changes of epithelial cells were seen in the nuclei (enlarged, hyperchromatic nuclei, anisonucleosis, multinucleation, wrinkled nuclear membrane, karyolysis: swollen nuclei resulting in a less intense staining reaction due to imbibition of fluid, karyorrhexis: fragmentation of the chromatin, karyopyknosis and shrinkage on less than $6 \mu$; all last four features are degenerative changes), and in the cytoplasm (eosinophilia, polychromasia, vacuolization, perinuclear halo, frayed cytoplasmic borders). Additionally, increased nuclear/cytoplasmic ratio with or without hyperchromasia was observed (Figures 1,2,3).

Inflammatory process was followed by reparative process resulting in regeneration of the cervical epithelium. 


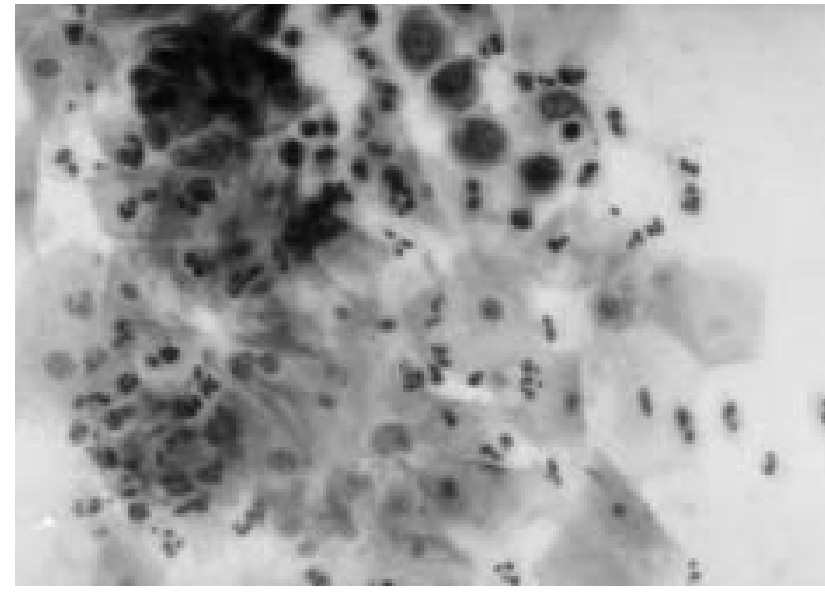

Fig.1: Cervical smear: Trichomonas infection. Cervicitis (PAPx40).

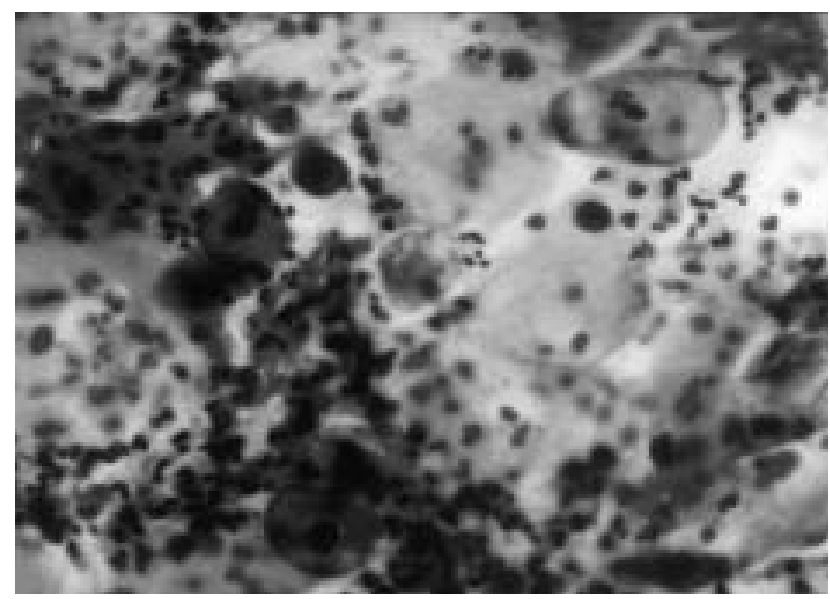

Fig. 2: Cervical smear: Parabasal squamous cells with karyopyknosis and a polymorphonuclear infiltrate. Cervicitis (PAPx40).

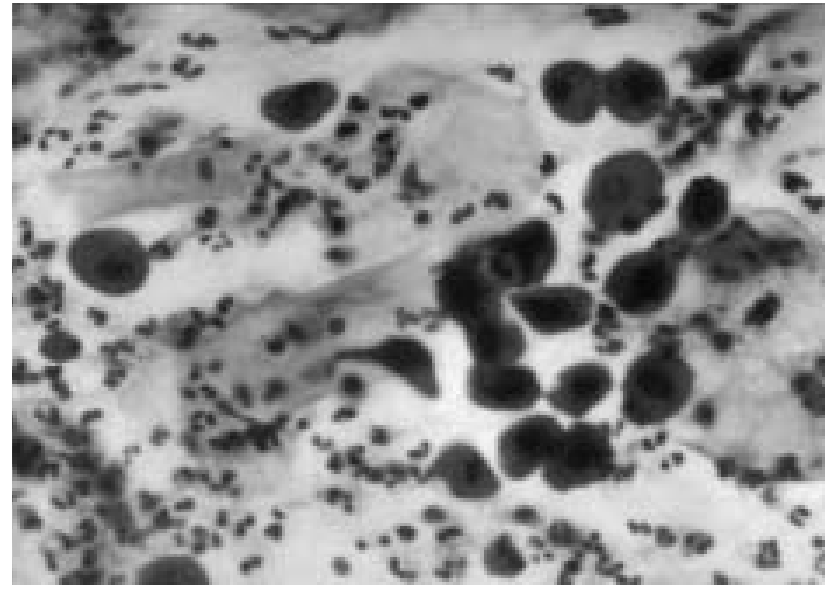

Fig. 3: Cervical smear: Parabasal squamous cells with karyopyknosis cervicitis (PAPx40).

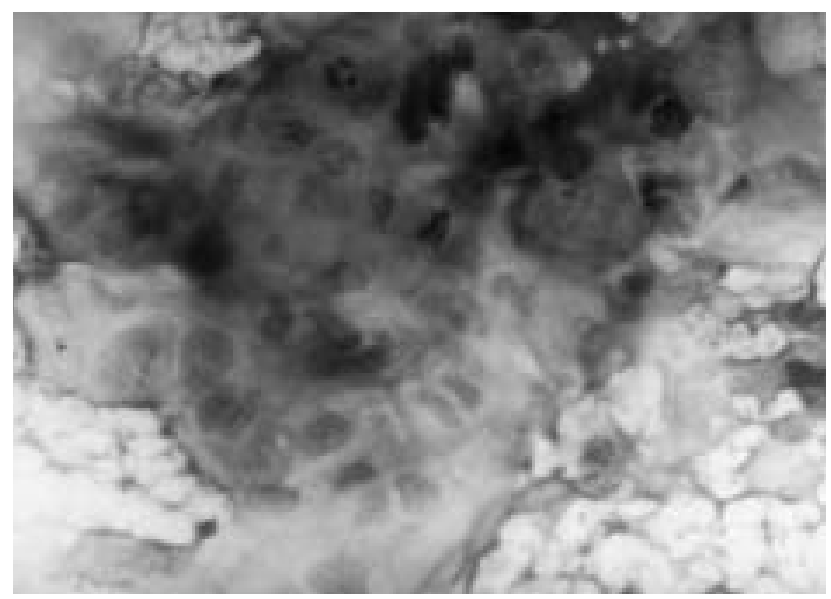

Fig. 4: Cervical smear: Dyskaryotic cells of intermediate type. CIN2 (PAPx40).

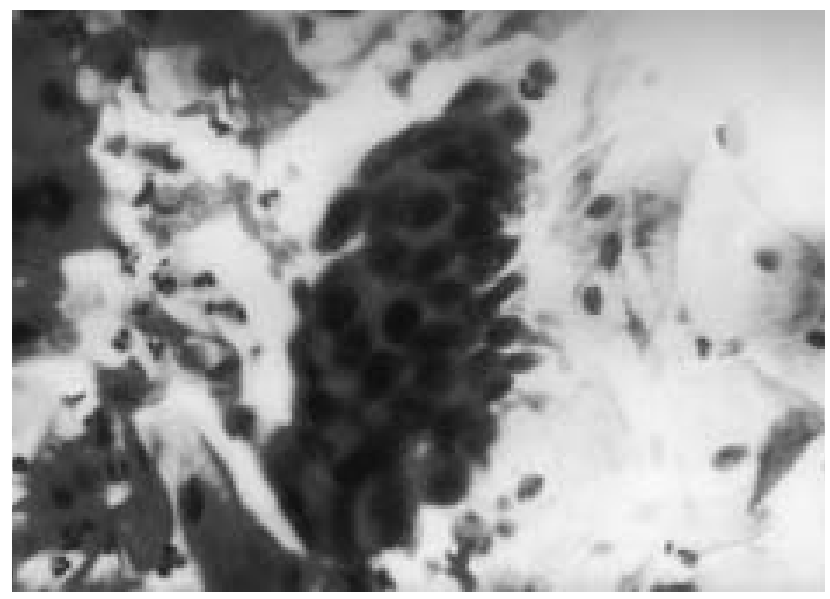

Fig. 5: Cervical smear: Undifferentiated cells with variation in size and shape, loss of polarity and overlapping. CIN3 (PAPx40). 
Sheets of cells of basal or parabasal type with large nuclei and prominent nucleoli were seen. The cytoplasmic staining pattern was lost, so the cells appeared polychromatic or assumed a cyanophilic hue, and the background of the smear was clean $(2,4,13,14,18,22)$.

Histologic evaluation of ulcerative cervicitis: The first stage was characterized by hyperemia of the papillary vessels followed by polymorph infiltration of the surrounding tissue. The epithelial cells showed considerable degenerative changes leading to ulceration with purulent exudate. Consequent healing of the ulcerated epithelium was effected by proliferation of adjacent epithelium and extension from local gland crypts (4).

Cytologic and histologic interpretation of the HPVinfection and CIN grades was based upon the classical criteria (4) (Figures 4,5).

Smears were evaluated upon well established cytomorphological features:

I Nuclear /cytoplasmic ratio

II Loss of polarity in cell clusters

III Chromatin pattern (fine,coarse)

IV Pleomorphism in cell shape

V Cellularity (low, moderate, high)

VI Smear pattern (clusters, single cells, papillary or glandular structures)

VII Anisocytosis (pleomorphism in cell size)

VIII Nucleoli (indistinct, distinct single or multiple)

IX Hyperchromasia (within normal limits, moderate, severe)

Tab. 1: Correlation of histology and cytology in ulcerative cervicitis, HPV-infection and CIN $(1,2,3)$.

\begin{tabular}{|lc|c|c|c|c|c|}
\hline \multicolumn{2}{|c|}{ Histology } & \multicolumn{5}{c|}{ CYTOLOGY } \\
& Cervicitis & HPV & CIN 1 & CIN 2 & CIN 3 \\
\hline Cervicitis & 38 & 31 & 2 & 2 & 1 & 2 \\
HPV & 4 & - & 4 & - & - & - \\
CIN 1 & 4 & - & - & 4 & - & - \\
CIN 2 & 1 & - & - & - & 1 & - \\
CIN 3 & 11 & - & - & - & - & 11 \\
\hline Total & 58 & 31 & 6 & 6 & 2 & 13 \\
\hline
\end{tabular}

Tab. 2: Correlation of the cytomorphologial features with the severity of the histological lesion.

\begin{tabular}{|l|c|}
\hline Nuclear /cytoplasmic ratio & +++ \\
\hline Loss of polarity in cell clusters & +++ \\
\hline Chromatin pattern (fine,coarse) & ++ \\
\hline Pleomorphism in cell shape & ++ \\
\hline Cellularity (low, moderate, high) & + \\
\hline $\begin{array}{l}\text { Smear pattern (clusters, single cells, papillary } \\
\text { or glandular structures) }\end{array}$ & - \\
\hline Anisocytosis (pleomorphism in cell size) & - \\
\hline Nucleoli (indistinct, distinct single or multiple) & - \\
\hline $\begin{array}{l}\text { Hyperchromasia (within normal limits, moderate, } \\
\text { severe) }\end{array}$ & - \\
\hline
\end{tabular}

+++ strong, ++ sufficient, + poor, - no correlation

\section{Results}

Results are shown at Table 1. There was a discrepancy between cytology and histology in the diagnosis of ulcerative cervicitis ( 31 cases to 38 cases). Based on histology, 7 cases $(18.42 \%)$ of ulcerative cervicitis were overdiagnosed by cytology. Two cases were interpreted as HPV-infection (5.26 \%), 2 as CIN1 (5.26\%), 1 as CIN2 (2.63\%) and 2 as CIN3 (5.26\%). There was no statistically significant difference between the two methods in the diagnosis of ulcerative cervicitis ( $p>0.5$, chi-square).

In the cases of HPV-infection and CIN grades there was an excellent agreement (100\%) between cytology and histology; 4 cases of HPV-infection, 4 cases of CIN1, 1 case of CIN2 and 11 cases of CIN3.

The correlation between cytological features and severity of the histological lesion is shown at Table 2. It was found that the following features were strongly correlated with the severity of the histological lesion: nuclear/cytoplasmic ration, loss of polarity. A poor correlation was found concerning cellularity. On the contrary, smear pattern, anisocytosis, nucleoli and hyperchromasia were not correlated with severity alone.

\section{Discussion}

In the evaluation of a cervicovaginal smear, careful screening of all fields of the smear and interpretation of the morphology of the cells one by one is mandatory. The cytological definition of a squamous or a glandular lesion of the cervix depends upon the appraisal of many criteria, e.g. multinucleated cells are not only seen in viral infections (HPV, herpes) but also in giant cells (giant histiocytes), syncytiotrophoblasts, squamous metaplasia, radiation therapy, CIN and invasive squamous carcinoma of the cervix.

Inflammatory changes not infrequently give rise to an erroneous diagnosis of CIN. Diagnostic pitfalls in the cytologic interpretation of ulcerative cervicitis are inflammatory changes of epithelial cells; nucleomegaly, hyperchromasia, and abnormal chromatin pattern due to intranuclear coagulation necrosis. The distinction between dyskaryosis and inflammatory change depends on careful examination of the nuclei of the cells. Dyskariotic cells show a degree of pleomorphism, rarely seen in inflammatory smears. If doubt remains, a report of borderline changes should be given and follow-up advised.

Regenerative changes in the cervical epithelium can also result in exfoliation of cells with active nuclei and large nucleoli. The uniformity of the cellular changes will be apparent in regenerating epithelial cells.

In our series there was found a cytological overdiagnosis $(18.42 \%)$ in ulcerative cervicitis correlating with histology. On the contrary a very strong correlation with histology ( $100 \%)$ was found in the cases of HPV-infection and CIN $(1,2,3)$ respectively, not consistent with the reported in the literature $(2.4 \%-71 \%)(1,8,11,15,17,19,21)$, 
obviously due to the small number of cases included in the study.

Some of the reasons of discrepancies between cytology and histology depend on factors such as the skill of taking and interpreting the smear, the size of the lesions, the location of lesions high up within the endocervical canal and the failure of some lesions to shed abnormal cells $(3,5,6$, $9,12,20,23)$. An interesting observation was made by Rubio (20) who stated that scraping of the surface of the surgical specimens containing carcinoma in situ failed to yield tumor cells in about half of the cases. In this study, review of all cervical smears from the 282 women failed to reveal any significant change in the interpretation of final diagnosis of the smears.

Nowadays, there must be stressed the attempt of the assessment of cervicography and telecolposcopy as triage methods with the application of some new parameters such as HPV DNA typing and liquid cytology in order to achieve a very high accuracy rate in cervical screening $(7,10,16)$.

\section{References}

1. Al Nafussi AI, Colquhoun MK. Mild cervical intraepithelial neoplasia (CIN 1), a histological over diagnosis. Histopathology 1990;17:557-61.

2. Atkinson BF, Silverman JF. Atlas of difficult diagnoses in Cytopathology. Pennsylvania, Philadelphia: WB Saunders Company, 1998.

3. Beilby JOW, Bourne R, Guilleband J, Steele ST. Paired cervical smears, a method of reducing the false negative rate in population screening. Obstet Gynaecol 1982;60:46-8.

4. Colleman DV, Evans DMD. Biopsy pathology and cytology of the cervix London: Chapman and Hall Medical, 1989.

5. Coppleson LW, Brow B. Estimation of the screening error rate from the observed detection rates in repeated cervical cytology. Am J Obstet Gynaecol 1974;119: 953-8.

6. Evans AS, Wells M. False negative cervical cytology obtained at colposcopy J Obstet Gynaecol 1982;3:114-6.

7. Giard RWM. False-negative rate of cervical cytology:sense and sensitivity. Diagn Cytopathol 2001;25:275-7 (editorial)

8. Giles JA, Hudson E, Crow J, Williams D, Walker P. Colposcopic assessment of the accuracy of cervical cytology screening. Br Med J 1988;269:1099.
9. Gupta DK, Komaromy-Hiller G, Raab SS, Nath ME. Interobserver and intraobserver variability in the cytologic diagnosis of normal and abnormal mataplastic squamous cells in pap smears. Acta Cytol 2000;45:697-703.

10. Harper DM, Moncur MM, Harper WH, Burke GC, Rasmussen CA, Mumford MC. The technical performance and clinical feasibility of telecolposcopy. J Fam Pract 2000;49:623-6.

11. Hill EC. Preclinical cervical carcinoma, colposcopy and the negative smear. Am J Obstet Cynaecol 1966;95:308-19.

12. Husain OA, Butler EB, Evans DM, Macgregor JE, Yule R. Quality control in cervical cytology. J Clin Pathol 1974;27:935-44.

13. Ismail SM, Colclough AB, Dinnen JS et al. Reporting cervical intra-epithelial neoplasia (CIN), intra- and interpathologist variation and factors associated with disagreement. Histopathology 1990;16:371-6.

14. Korn AP, Judson PL, Zaloudek CJ. Importance of atypical glandular cells of uncertain significance in cervical cytologic smears. J Reprod Med 1998;43(9): 774-8.

15. Koss LG. Diagnostic cytology and its histopathological basis. Philadelphia: Lippincott, 1992

16. Mould TA, Singer A, Mansell ME, Gallivan S. Cervicography to triage women with borderline or mild dyskaryotic cervical PAP smears. Eur J Cynecol Oncol 2000;21:264-6.

17. Richard RM. Evaluation of the true false negative rate in cytology. Am J Obstet Cynaecol 1964;89:723-6.

18. Richards CJ, Furness PN. Basement membrane continuity in benign, premalignant and malignant epithelial conditions of the uterine cervix. Histopathology $1990 ; 16: 47-52$

19. Robertson JH, Woodend BE, Crozier EH, Hutchinson J. Risk of cervical cancer associated with mild dyskaryosis. Br Med J 1988;279:18-21.

20. Rubio CA. The false negative smear (Letter to the Editor). Am J Obstet Gynaecol 1974;119:273.

21. Rylanden E. Cervical cancer in women belonging to a cytologically screened population. Acta Obstet Gynaecol Scand 1976;55:361-6.

22. Vilches K, Escalona A. Evolution of atypical gynecological cervical smears in a captive population. Rev Med Chil 1998;126(3):296-301.

23. Walker EM, Dodgson J, Duncan ID. Does mild atypia on a cervical smear warrant further investigation? Lancet 1986;II:672-3.

Submitted August 2003. Accepted October 2003.

Demetrio Tamiolakis, M.D., Kissamou 11, 73136, Chania, Krete, Greece. e-mail: cyto@chaniahospital.gr 